Article

\title{
Effects of Ultrasonication on the Conformational, Microstructural, and Antioxidant Properties of Konjac Glucomannan
}

\author{
Jun-Yi Yin ${ }^{1,2}$, Lu-Yao Ma ${ }^{2}$, Ka-Chai Siu ${ }^{1}$ and Jian-Yong Wu ${ }^{1, * \mathbb{D}}$ \\ 1 Department of Applied Biology and Chemical Technology, The Hong Kong Polytechnic University, \\ Kowloon 999077, Hong Kong, China; yinjy@ncu.edu.cn (J.-Y.Y.); ka-chai.siu@polyu.edu.hk (K.-C.S.) \\ 2 State Key Laboratory of Food Science and Technology, Nanchang University, Nanchang 330047, China; \\ maluyaoo@163.com \\ * Correspondence: jian-yong.wu@polyu.edu.hk
}

Received: 28 December 2018; Accepted: 28 January 2019; Published: 29 January 2019

\begin{abstract}
This study aims to evaluate the effects of ultrasonication (US) on the conformational, microstructural, and antioxidant properties of konjac glucomannan (KGM). US treatment with a $20-\mathrm{kHz}$ and $750-\mathrm{W}$ ultrasonic processor at $60 \%$ amplitude was applied for partial degradation of KGM with an average molecular weight (MW) of $823.4 \mathrm{kDa}$. Results indicated that the US treatment caused dramatic reduction in the MW, apparent viscosity, hydrodynamic radius, and z-average mean radius of gyration. The flexibility of chain conformation of native KGM was slightly increased during the US treatment. According to electronic microscopic imaging, the compact, smooth, and orderly fibrous strings formed by KGM were changed to amorphous, porous flakes and globular particles after US treatment. KGM and its US-treated fractions showed moderate radical-scavenging and ferric-reducing antioxidant activity. US degradation of KGM affected these activities either positively or negatively, depending on the US treatment period. In summary, ultrasonic degradation of KGM caused changes in its conformation characteristics, microstructure, and antioxidant activities.
\end{abstract}

Keywords: ultrasonic treatment; konjac glucomannan; conformation; microstructure; antioxidant activity

\section{Introduction}

Konjac glucomannan (KGM) is a water-soluble polysaccharide originated from the plant tuber of Amorphophallas konjac. The polysaccharide chain of KGM is composed of 1,4-linked $\beta$-D-mannopyranose and $\beta$-D-glucopyranose backbone with a mannose and glucose molar ratio of 1.4 to 10 [1-4]. KGM is widely used in pharmaceutical, biotechnological, fine chemical, and other fields because of its excellent biocompatibility and biodegradable activities [5]. Moreover, it is recognized as a promising dietary fiber supplement and functional food for gut health, body weight management, and type 2 diabetes treatment [6-10]. However, native KGM has a very limited range of functionality. Therefore, its modifications attracted increasing attention for expanding its functions and applications [11].

Chemical and physical methods are frequently applied to modify KGM [11]. Sulfated KGM was shown to have potent anti-human immunodeficiency virus (HIV) activity and moderate blood anticoagulant activity [12]. Oxidized KGM and its acidolysis products exerted immune responses to Schizothorax prenanti infected by Aeromonas hydrophila [13]. Consumption of depolymerized KGM has been shown to enhance wound healing for mice [14]. Acid-hydrolyzed KGM exhibited a greater prebiotic effect on the modulation of cecal and fecal microflora than did original KGM in mice [15]. 
On the other hand, physical methods such as $\gamma$-irradiation, ultrasonication (US), and extrusion were used to modify KGM. Degraded KGM prepared by $\gamma$-irradiation was demonstrated to be more effective in protecting the $\mathrm{LO} 2$ cell line (human hepatic cell line) against $\mathrm{H}_{2} \mathrm{O}_{2}$-induced oxidative damage [16]. US-degraded KGM had stronger protective effects on Bifidobacteria against antibiotic damage [17]. Extrusion modification was able to reduce the molecular weight, water absorption index, and viscosity of KGM [18].

As sonochemistry is used in several chemical, physical, and biological processes [19], ultrasonic (US) treatment was effective for partial degradation of polymer compounds, reducing the molecular weight and viscosity but not causing any significant changes in the chemical nature [20]. It has been widely explored for the modification and partial degradation of carbohydrate polymers including various natural polysaccharides $[20,21]$. Sonication usually breaks polymer chains at the center point or at the structurally weakest points. The polymer at a high molecular weight or with a longer chain is degraded more rapidly by US. A linear polymer chain was found more easily degraded with US than branched ones [22]. The degradation kinetics can be fitted to either a midpoint chain scission model or a random chain scission model [23].

A previous study of our group showed the effects of power ultrasound on the molecular weight and rheological properties of KGM [24]. Based on this, the aim of the present study was to further investigate the effects of US treatment on the solution properties of KGM, particularly its conformation characteristics and microstructure in water. The effects of US treatment on the bioactivity of KGM have rarely been reported except the studies reported by Mao et al. and Song et al. [17,25], the influence of US degradation on the antioxidant activity of KGM was evaluated using in vitro assays. The investigation will be helpful for a better understanding of the degradation mechanisms and the effects of US on the functional properties of KGM.

\section{Materials and Methods}

\subsection{Materials}

KGM (containing about $8 \%$ acetyl groups, with a molecular weight (MW) of $823.4 \mathrm{kDa}$ ) was kindly provided by Hubei Konson Konjac Gum Co., Ltd. (Wuhan, China). The molar ratio of mannose (Man) to glucose (Glc) (M/G) was 1.3 (Table S1, Supplementary Materials).

Reference standards of monosaccharides and derivatives (L-fucose, L-rhamnose, D-arabinose, D-galactose, D-glucose, D-mannose, D-fructose, D-galacturonic acid, and D-glucuronic acid), and trifluoroacetic acid (TFA) were purchased from Merck Corp. (Darmstadt, Germany) and Sigma Chemical Corp. (St. Louis, MO, USA). Furthermore, 2,2'-diphenyl-1-picrylhydrazyl (DPPH), 2,2'-azinobis-3-ethyl-benzothiazoline-6-sulphonate (ABTS), and 6-hydroxy-2,5,7,8-tetramethylchroman2-carboxylic acid (Trolox) were obtained from Sigma Chemical Corp. (St. Louis, MI, USA).

\subsection{Composition Analysis of KGM}

Saccharide content of KGM was determined using the phenol-sulfuric acid method [26] with Man as a standard, and the total protein content was measured using a photometric assay [27] with bovine serum albumin (BSA) as a standard. The acetyl group content was determined using a titration method [28]. Monosaccharide composition was analyzed using a high-performance anion-exchange chromatograph with pulsed amperometric detection (HPAEC-PAD) as reported previously [29]. The KGM sample ( $5 \mathrm{mg}$ ) was initially hydrolyzed in $0.5 \mathrm{~mL}$ of $12 \mathrm{M} \mathrm{H}_{2} \mathrm{SO}_{4}$ solution for $0.5 \mathrm{~h}$ at $100{ }^{\circ} \mathrm{C}$ and then diluted with $2.0 \mathrm{~mL}$ of ultrapure water, and further hydrolyzed for $2 \mathrm{~h}$. The hydrolysate was applied to monosaccharide analysis using a Dionex ICS-5000 System (Dionex Corporation, CA, USA), which was equipped with a CarboPac ${ }^{\mathrm{TM}}$ PA20 guard column $(3 \mathrm{~mm} \times 30 \mathrm{~mm})$ and a CarboPac ${ }^{\mathrm{TM}}$ PA20 analytical column $(3 \mathrm{~mm} \times 150 \mathrm{~mm})$ in series [30]. 


\subsection{Ultrasonic Degradation of KGM}

KGM ( 0.9 g) was mixed with distilled water $(300 \mathrm{~mL})$ and heated at $70{ }^{\circ} \mathrm{C}$ for $2 \mathrm{~h}$, and was kept at room temperature under stirring for another $12 \mathrm{~h}$ to attain a homogenous solution. The KGM solution was centrifuged at 10,000 $\mathrm{rpm}(\sim 15,344 \times g)$ to remove any undissolved residues. The final KGM solution was transferred into a $50 \mathrm{~mL}$ plastic centrifuge tube at $30 \mathrm{~mL}$ filling volume for US treatment. The US treatment was performed using a Model VCX-750 ultrasonic processor with a frequency of $20 \mathrm{kHz}$ (Sonics \& Materials Inc., Newton, USA) and at a fixed power controlled at $60 \%$ amplitude, as previously reported [22]. The ultrasonic probe (tip diameter: $6 \mathrm{~mm}$ ) was submerged into the KGM solution at a fixed depth of $2 \mathrm{~cm}$. The sample tube was placed in an ice bath during the US treatment.

\subsection{Analysis of MW and Conformation Parameters}

KGM before and after ultrasonic degradation was dissolved in $0.1 \mathrm{M} \mathrm{NaNO}_{3}$ containing $0.02 \%$ $(w / w) \mathrm{NaN}_{3}$ for more than $24 \mathrm{~h}$, before being filtered through a $0.22 \mu \mathrm{m}$ membrane and applied for high-performance size-exclusion chromatography (HPSEC) analysis [31]. The HPSEC instrument system consisted of a multi-angle laser light scattering (MALLS) detector (wavelength of $663.6 \mathrm{~nm}$, eighteen angles) (Dawn Heleos II, Wyatt), a refractive index (RI) detector (OPTILAB T-rEX, Wyatt), and a viscometer (Visco Star II, Wyatt). Three SEC columns in series were used including an Ohpak SB-G guard column $(8 \times 50 \mathrm{~mm})$, an Ohpak SB-806 HQ column $(8 \times 300 \mathrm{~mm})$, and an Ohpak SB-804 HQ column $(8 \times 300 \mathrm{~mm})$ from Showa Denko K.K. (Tokyo, Japan), with the temperature being maintained at $35^{\circ} \mathrm{C}$. The eluent was $0.1 \mathrm{M} \mathrm{NaNO}_{3}$ solution containing $0.02 \%(w / w) \mathrm{NaN}_{3}$ at a flow rate of $0.6 \mathrm{~mL} / \mathrm{min}$. Data were collected and analyzed using the ASTRA software (Version 6.1.1.84), normalized with dextran from Leuconostoc mesenteroides (average MW: 35,000-45,000) (Sigma, St. Louis, USA). An RI increment $(d n / d c)$ of 0.146 was used in the calculation.

\subsection{Rheological Measurement}

KGM samples were dissolved in ultrapure water at $55{ }^{\circ} \mathrm{C}$ with constant stirring. The sample solution was kept at $25^{\circ} \mathrm{C}$ for more than $12 \mathrm{~h}$ before measurement. The measurement was operated with a strain-controlled rheometer (ARES-G2, TA instrument, Newcastle, DE, USA) equipped with parallel plate geometry ( $40 \mathrm{~mm}$ diameter, $1.0 \mathrm{~mm}$ gap) or cone plate geometry (50 $\mathrm{mm}$ diameter, $0.046 \mathrm{~mm}$ gap). A steady shear test was applied for the determination of flow behaviors at $25.0^{\circ} \mathrm{C}$.

\subsection{Fourier-Transform Infrared Spectroscopy and Scanning Electronic Microscope Observation}

Fourier-transform infrared (FTIR) spectra of KGM samples were recorded using a Thermo Nicolet 5700 IR spectrophotometer (Thermo-Electron, Madison, USA) in wavenumbers ranging from $4000 \mathrm{~cm}^{-1}$ to $400 \mathrm{~cm}^{-1}$ at a resolution of $4 \mathrm{~cm}^{-1}$.

KGM was dissolved at $1.0 \mathrm{mg} / \mathrm{mL}$ and placed into liquid nitrogen for $10 \mathrm{~min}$ and freeze-dried. The dried samples were prepared with platinum sputter coating, and imaged using a JSM-6701F scanning electronic microscope (SEM) (Jeol Company, Tokyo, Japan) at an accelerating voltage of $5 \mathrm{kV}$.

\subsection{Antioxidant Activity Assays}

All samples of KGM and US-degraded fractions were dissolved in distilled water to various concentrations $(0.125-2.0 \mathrm{mg} / \mathrm{mL})$ for antioxidant activity assays. All assays were performed according to reported procedures with slight modifications [32] for DPPH radical-scavenging activity, [33] for ABTS radical-scavenging activity, and for ferric-reducing antioxidant power. The radical-scavenging activity $(\%)$ was represented by $\left(1-\left(\mathrm{A}_{2}-\mathrm{A}_{1}\right) / \mathrm{A}_{0}\right) \times 100$, where $\mathrm{A}_{0}, \mathrm{~A}_{1}$, and $\mathrm{A}_{2}$ were the absorbance values of the control (DPPH solution), solvent blank (ethanol), and the tested KGM sample, respectively. 


\section{Results and Discussion}

\subsection{Effect of US on MW Distribution of KGM}

Figure 1 and Table 1 show the results from the HPSEC-MALLS-Vis-RI analysis of KGM fractions before and after US treatment. The MW of KGM was significantly reduced with the increase in sonication time. Meanwhile, the polydispersity index $M_{\mathrm{w}} / M_{\mathrm{n}}$ value of KGM decreased with increasing sonication time, indicating a narrower or more uniform MW distribution. Similarly, the MW distribution of KGM became narrower upon ultrasonic degradation [34,35]. Usually, shear forces produced from the rapid collapse of cavitation bubbles in the liquid due to ultrasonication are mainly responsible for the disruption of the polymer aggregates and breakage of polymer chains in solution [20,36].

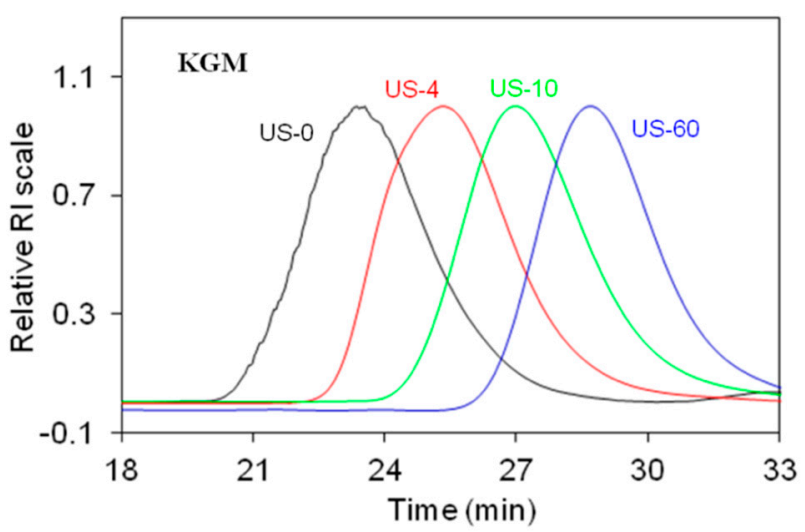

Figure 1. High-performance size-exclusion chromatography (HPSEC) chromatograms of konjac glucomannan (KGM) fractions (US-0, US-4, US-10, and US-60: ultrasonication (US) treatment for $0,4,10$, and $60 \mathrm{~min}$ at a fixed amplitude of $60 \%$ ).

Table 1. Effects of ultrasonication (US) on molecular properties and conformation of konjac glucomannan (KGM) fractions derived from analysis with high-performance size-exclusion chromatography (HPSEC) equipped with multi-angle laser light scattering (MALLS) detector, viscometer (Vis), and refractive index RI detector. MW—-molecular weight.

\begin{tabular}{cccccc}
\hline $\begin{array}{c}\text { Sonication } \\
\text { Time (min) }\end{array}$ & $\boldsymbol{M}_{\mathbf{w}} / \boldsymbol{M}_{\mathbf{n}}$ & $\boldsymbol{R}_{\mathbf{h}}(\mathbf{n m})$ & $\left\langle\boldsymbol{R}_{\mathbf{g}}\right\rangle_{\boldsymbol{z}}(\mathbf{n m})$ & \multicolumn{2}{c}{ Higher-MW Region } \\
\cline { 5 - 6 } & & & & $\alpha$ & $\boldsymbol{L}_{\mathbf{p}}(\mathbf{n m})$ \\
\hline 0 & 1.5 & 60.0 & 104.5 & 0.79 & 10.3 \\
2 & 1.3 & 33.6 & 55.9 & 0.51 & 7.1 \\
4 & 1.3 & 22.7 & 39.6 & 0.62 & 7.2 \\
6 & 1.3 & 19.7 & 33.3 & 0.65 & 7.4 \\
10 & 1.2 & 16.5 & 28.7 & 0.69 & 7.4 \\
20 & 1.2 & 13.8 & 25.4 & 0.73 & 7.3 \\
30 & 1.2 & 12.9 & 24.9 & 0.77 & 7.5 \\
60 & 1.2 & 11.1 & 26.9 & 0.95 & 9.1 \\
\hline
\end{tabular}

a MW distributions selected for $\alpha$ values and $L_{\mathrm{p}}$ calculation were based on Mark-Houwink plots shown in Figures S2 and S3 (Supplementary Materials); $\alpha$ was calculated from the Mark-Houwink equation; $L_{\mathrm{p}}$ was the persistence length.

\subsection{Degradation Kinetics and Chain Scission Mechanisms}

The intrinsic viscosity and MW of KGM fractions decreased rapidly in the initial period of US treatment ( $\leq 20 \mathrm{~min}$ ) and then slowly in the remaining period (Figure $2 a, b)$. In Figure $2 b$, the initial value of $[\eta]$ for $\mathrm{KGM}$ was $1803.5 \mathrm{~mL} \cdot \mathrm{g}^{-1}$, which was close to values reported by Kishida et al. [37] (18.6-19.9 dL·g $\left.{ }^{-1}\right)$, Maeda et al. [3] (12.7-23.6 dL·g $\left.{ }^{-1}\right)$, and Ratcliffe et al. [38] (16.0-20.0 dL·g $\left.{ }^{-1}\right)$, but higher than values determined by Kök et al. [39] $\left(7.65-13.0 \mathrm{dL} \cdot \mathrm{g}^{-1}\right)$. 
Ultrasonic degradation of polymers follows two primary chain scission mechanisms: random chain scission and midpoint chain scission [40]. The degradation kinetics for random chain scission can be represented by the classical Schmid model relating the rate of degradation to MW [41].

$$
\frac{M_{e}}{M_{t}}+\ln \left(1-\frac{M_{e}}{M_{t}}\right)=\frac{M_{e}}{M_{i}}+\ln \left(1-\frac{M_{e}}{M_{i}}\right)-\frac{k_{1}}{c}\left(\frac{M_{e}}{m}\right)^{2} t,
$$

where $M_{\mathrm{i}}$ and $M_{t}$ represent the initial average MW and the MW at time $t$ of the US treatment, respectively, $M_{\mathrm{e}}$ is the final limiting average MW, $m$ represents the MW of the monomer, $c$ is the initial molar concentration of the polymer, and $k_{1}$ is the degradation rate constant. With this model equation, the plot of $-\left(M_{\mathrm{e}} / M t\right)-\ln \left(\left(1-\left(M_{\mathrm{e}} / M t\right)\right.\right.$ versus time $t$ is linear. For midpoint chain scission, the degradation kinetics can be represented by the following first-order kinetic model [42]:

$$
\ln \left(\left(M_{\mathrm{i}}-M_{\mathrm{e}}\right) /\left(M_{t}-M_{\mathrm{e}}\right)\right)=k M_{\mathrm{e}} t
$$

The final limiting MW $M_{\mathrm{e}}$ value for the KGM fractions was attained upon US treatment of KGM for $2 \mathrm{~h}$ as 20.7. Figure $2 \mathrm{c}, \mathrm{d}$ show the plots and linear regression results of experimental data according to the model equations, $-\left(M_{\mathrm{e}} / M_{t}\right)-\ln \left(\left(1-\left(M_{\mathrm{e}} / M_{t}\right)\right.\right.$ versus $t$ for the random scission (Equation (1)) and $\ln \left(\left(M_{\mathrm{e}}-M_{\mathrm{i}}\right) /\left(M t-M_{\mathrm{i}}\right)\right)$ versus $t$ for the midpoint scission (Equation (2)), respectively. Obviously, the experimental data fitted closely to the random chain session model (Figure 2c) but not to the midpoint scission model (Figure 2d), suggesting that the US degradation of KGM was mainly achieved through the random chain scission mechanism. Similarly, random chain scission was also observed in previous studies for US degradation of KGM [22], pectin [43], and chitosan [40].
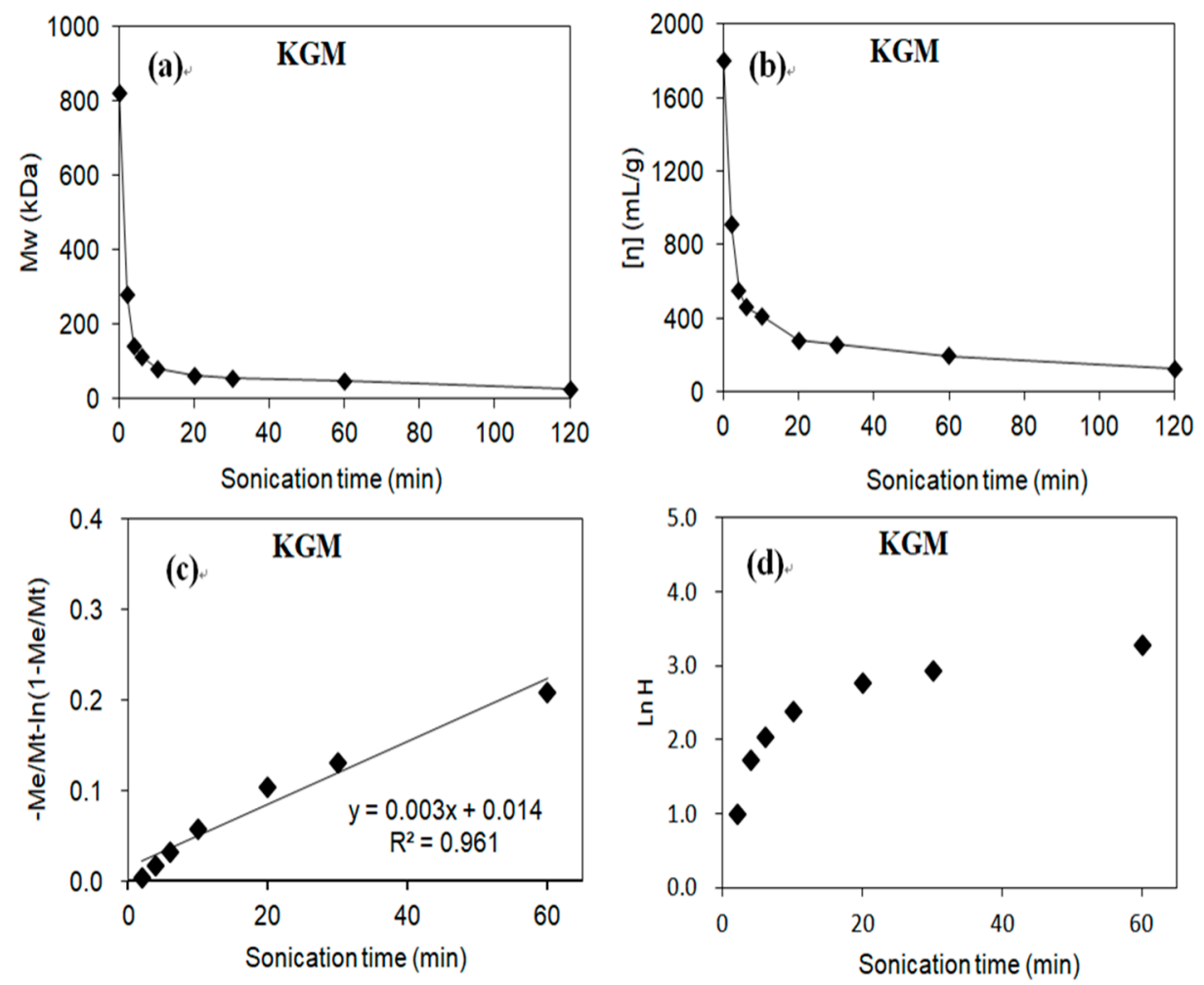

Figure 2. Kinetics of ultrasonic degradation of KGM: (a) time courses of molecular weight (MW) change during US treatment; (b) time courses of intrinsic viscosity $[\eta]$ change during US treatment; (c) MW time courses fitted to the random chain scission model Equation (1); (d) MW time courses fitted to the midpoint chain scission model Equation (2); H represents the value of $\left(M_{\mathrm{e}}-M_{\mathrm{i}}\right) /\left(M t-M_{\mathrm{i}}\right)$. 


\subsection{Effects of US on Rheological and Structural Characteristics of KGM}

Figure 3 displays the apparent viscosity versus shear rate of KGM solutions as a function of time under US treatment. All the original KGM fractions exhibited shear-thinning flow behavior at concentrations over $0.25 \%(w / v)$ and the apparent viscosity exceeded $1000 \mathrm{~Pa} \cdot \mathrm{s}$ at shear rate of $0.01 \mathrm{~s}^{-1}$. The apparent viscosity decreased rapidly upon US treatment. As the US treatment exceeded $4 \mathrm{~min}$, the apparent viscosity was flat versus the shear rate, indicating that the KGM solution was changed to a Newtonian fluid $(0.5 \%)$ with a constant viscosity independent of shear rate.

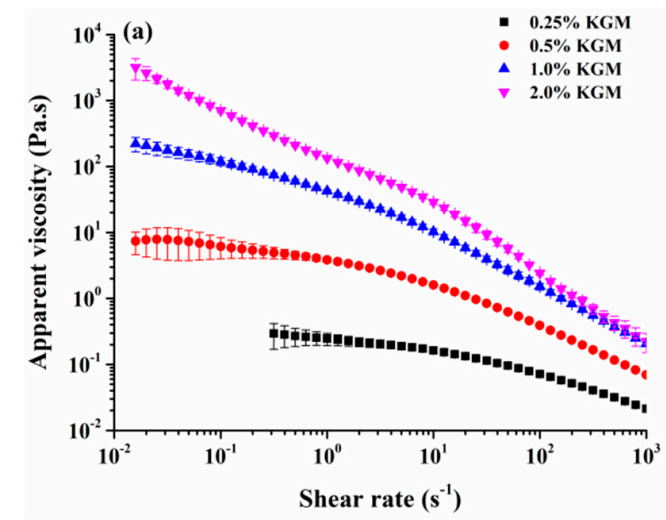

(a)

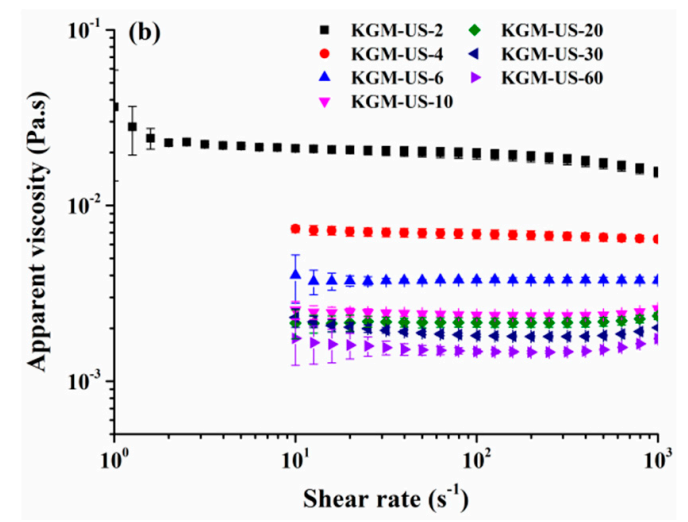

(b)

Figure 3. Apparent viscosities of original KGM and US-treated KGM. (a) Apparent viscosity of KGM; (b) apparent viscosities of US-treated KGM (KGM-US-2, KGM-US-4, KGM-US-6, KGM-US-10, KGM-US-20, KGM-US-30, and KGM-US-60). All samples were tested three times by flow sweep in the shear rate range of $0.01-1000 \mathrm{~s}^{-1}$ at $25^{\circ} \mathrm{C}$. All values are expressed as means $\pm \operatorname{SD}(n=3)$.

Figure 4 shows the FTIR spectra of KGM fractions before and after US treatment (for $10 \mathrm{~min}$ and $60 \mathrm{~min}$ ). The broad absorption peak at $3500-3000 \mathrm{~cm}^{-1}$ was attributed to $\mathrm{O}-\mathrm{H}$ stretching vibration of the inter- and intra-molecular hydrogen bonds of hydroxyl groups. The band around $2889 \mathrm{~cm}^{-1}$ was due to the $\mathrm{C}-\mathrm{H}$ stretching and bending vibration of methyl groups. Peaks at 1733,1369 , and $1254 \mathrm{~cm}^{-1}$ were assigned to the valence vibration of $\mathrm{C}=\mathrm{O}$, the symmetric $\mathrm{C}-\mathrm{H}$ bending vibration of the methyl group, and the $\mathrm{C}-\mathrm{O}$ vibration of $\mathrm{O}$-acetyl groups, respectively [44,45]. Most of these characteristic peaks were preserved after US treatment, suggesting that there was no significant alteration in the functional group types of KGM before and after US treatment.

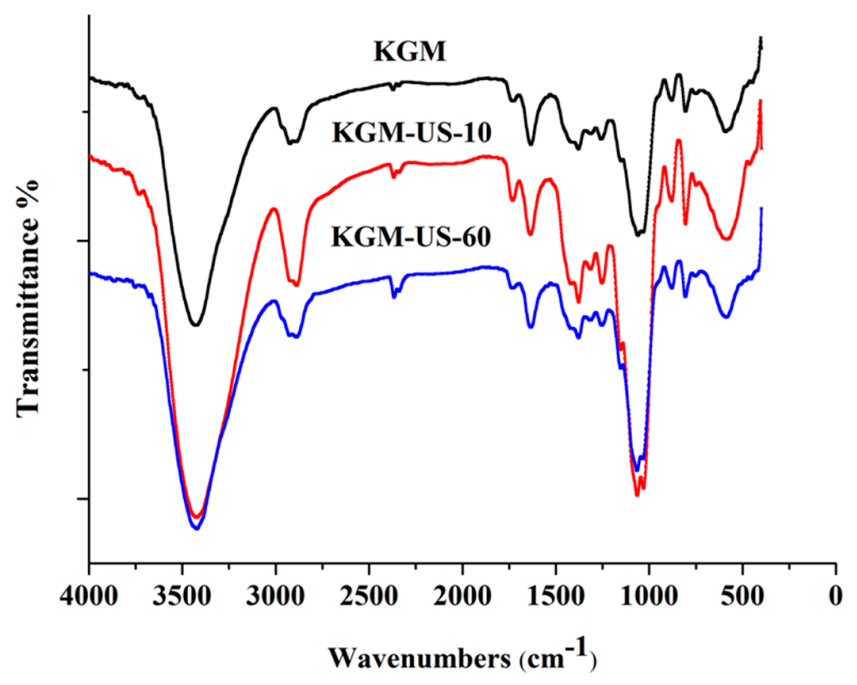

Figure 4. Fourier-transform infrared (FTIR) spectra of original KGM and US-treated KGM (KGM-US-10 and KGM-US-60). 


\subsection{Effect of US on Chain Conformation of KGM}

As shown in Table 1 , the hydrodynamic radius $R_{\mathrm{h}}$ and zeta-average radius of gyration $R_{\mathrm{g}}$ of KGM fractions decreased as the US treatment time was increased, indicating the size reduction of polymer aggregates. The three-dimensional shape of polymer in liquid can be related to the ratio, $\rho=R_{\mathrm{g}} / R_{\mathrm{h}}$. Usually, $\rho$ is about 0.77 for a uniform and non-draining sphere, 1.0-1.1 for a loosely connected hyper branched chain, 1.5-2.0 for a flexible chain in a good solvent, and $>2.0$ for an extended rigid chain [46]. The $R_{\mathrm{g}} / R_{\mathrm{h}}$ ratio fluctuated in the initial 10-20 min and showed a notable increase after $30 \mathrm{~min}$ of US treatment, i.e., the ratio for KGM went from 1.74 to 1.93 (30 min).

Intrinsic viscosity $[\eta]$ is related to the average MW via the Mark-Houwink equation, $[\eta]=K M^{\alpha}$. The exponent $\alpha$ value usually lies in the range of $0.5-0.6$ for random-coil polysaccharide chains, while $\alpha$ in the range of $0.7-0.8$ suggests that the polymer exists as a linear flexible chain in a good solvent. For a rigid or rod-like polymer, the chains are greatly extended in solution and the $\alpha$ value could be as high as $2.0[47,48]$. The $\alpha$ value was 0.79 for KGM. The notable increase in the $\alpha$ value of KGM after US treatment suggested that the polymer chains were greatly extended. KGM with a lower MW and viscosity was more homogeneous. After US treatment for over $2 \mathrm{~min}$, the $\alpha$ values of higher-MW sections of KGM fractions increased from 0.51 to 0.95 .

Persistence length $\left(L_{\mathrm{p}}\right)$ is defined as the average projection length along the initial direction of the polymer chain and it is a useful index for the linear flexibility of polysaccharide chain $[39,49]$. Based on the wormlike cylinder model for characterizing the conformation characteristics of polymers, $L_{\mathrm{p}}$ can be computed using the Bohdanecký plot of $\left(M^{2} /[\eta]\right)^{1 / 3}$ against $M^{1 / 2}$ according to the following equation [50]:

$$
\left(\frac{M^{2}}{[\eta]}\right)^{1 / 3}=A_{0} M_{L} \Phi_{0, \infty}-1 / 3+B_{0} \Phi_{0, \infty}-1 / 3\left(\frac{2 L_{p}}{M_{L}}\right)^{-1 / 2} M^{1 / 2}
$$

where $\Phi_{0, \infty}$ is equal to $2.86 \times 10^{23} \mathrm{~mol}^{-1}, M_{\mathrm{L}}$ is the mass per unit contour length of $330 \mathrm{~g} \cdot \mathrm{mol}^{-1} \cdot \mathrm{nm}^{-1}$, and $B_{0}$ can be replaced by the mean value of 1.10 [39]. The $L_{\mathrm{p}}$ value was $10.3 \mathrm{~nm}$ for the original KGM sample, suggesting it had a flexible chain conformation, which is in good agreement with a previous study [39]. For KGM after 2 min of sonication, the Bohdanecký plot was divided into two sections according to Mark-Houwink plot (Figure S1, Supplementary Materials), with a $L_{\mathrm{p}}$ value of $7.1 \mathrm{~nm}$ in higher-MW sections. As the sonication time exceeded $30 \mathrm{~min}$, the $L_{\mathrm{p}}$ value of KGM in the higher-MW region was still $7.5 \mathrm{~nm}$.

\subsection{Effect of US on the Microstructure of KGM}

Figure 5 presents the SEM images of KGM fractions before and after US treatment up to $60 \mathrm{~min}$. The original KGM exhibited orderly and relatively compact fibrous networks (Figure 5 and Figure S2, Supplementary Materials), which were quite different from microstructures for other glucomannans from konjac flour [51,52], probably due to different conditions for sample preparation. In the present study, the KGM sample solution for the SEM was placed in liquid nitrogen for $10 \mathrm{~min}$ before freeze-drying to maintain the chain structure. The microstructure of KGM fractions changed notably after sonication, from a linear morphology and orderly structure to particulate and amorphous particles. The particles were probably formed through the aggregation of shorter polymer chains of lower-MW fractions from US degradation. The microstructures shown by the SEM could partly explain the reduction in KGM viscosity and change in rheological behavior from the shear thinning fluid of the long polymer chains and large gel networks to the Newtonian fluid of well-dispersed and shorter fragments in water. 

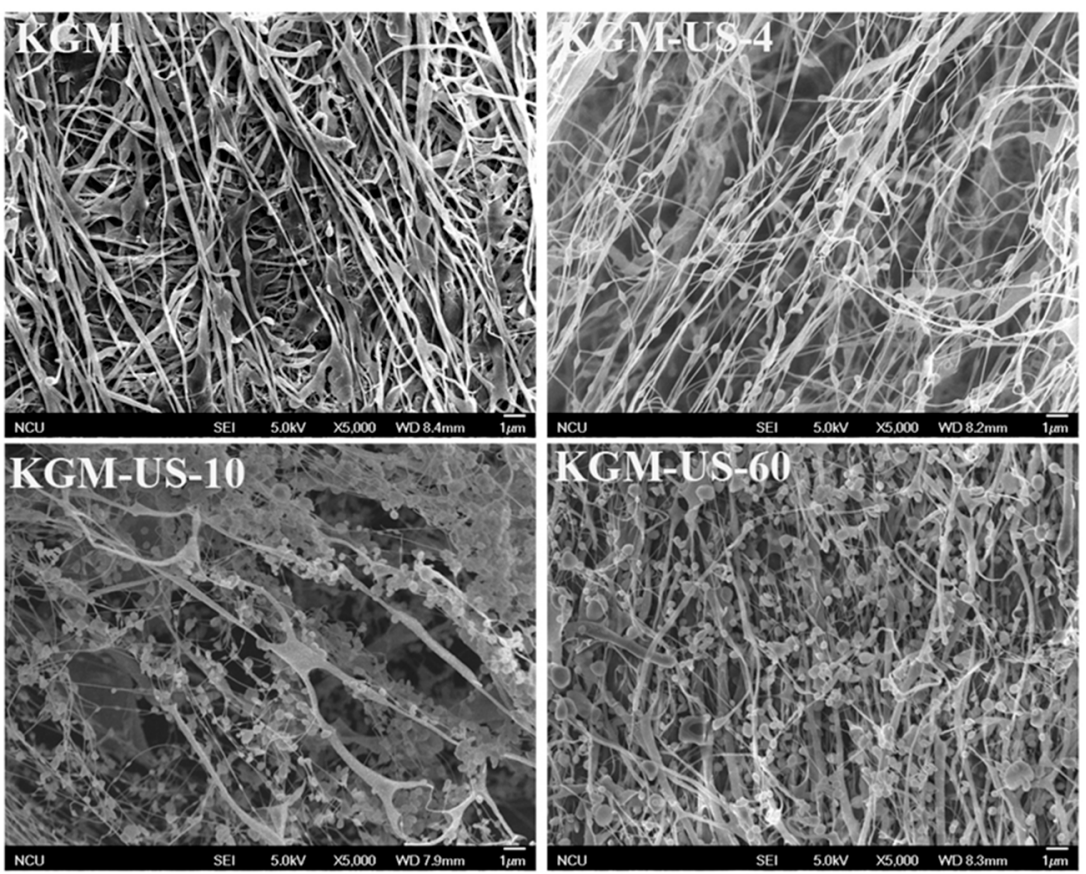

Figure 5. SEM images of original and US-treated KGM fractions (magnification $5000 \times$ ).

\subsection{US Treatment Effect on in Vitro Antioxidant Activity of KGM}

As shown in Figure 6, KGM before and after US treatment exhibited moderate scavenging activity against $\mathrm{DPPH}$ and $\mathrm{ABTS}^{+}$radicals and ferric-reducing power. The $\mathrm{ABTS}^{+}$radical-scavenging activity increased steadily with US treatment period from 2 to $60 \mathrm{~min}$. However, the DPPH scavenging activity and ferric-reducing power only increased with the US treatment for 2 min (KGM-US-2), but not consistently beyond this US treatment period, similar to a previous study on some other polysaccharides subjected to US treatment [53-55]. Overall the results suggest that US treatment of KGM improved the in vitro antioxidant activity, probably due to the reduction in MW, as shown in previous studies [55-57].
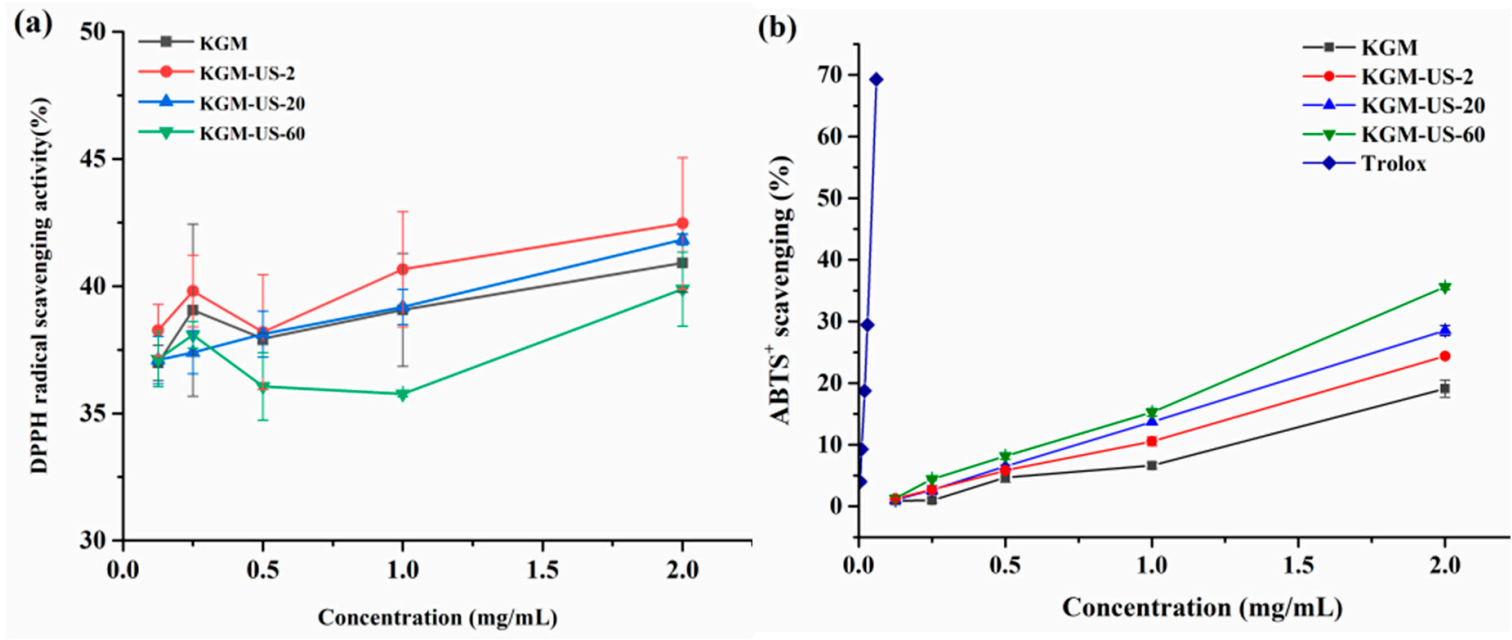

Figure 6. Cont. 
(c)

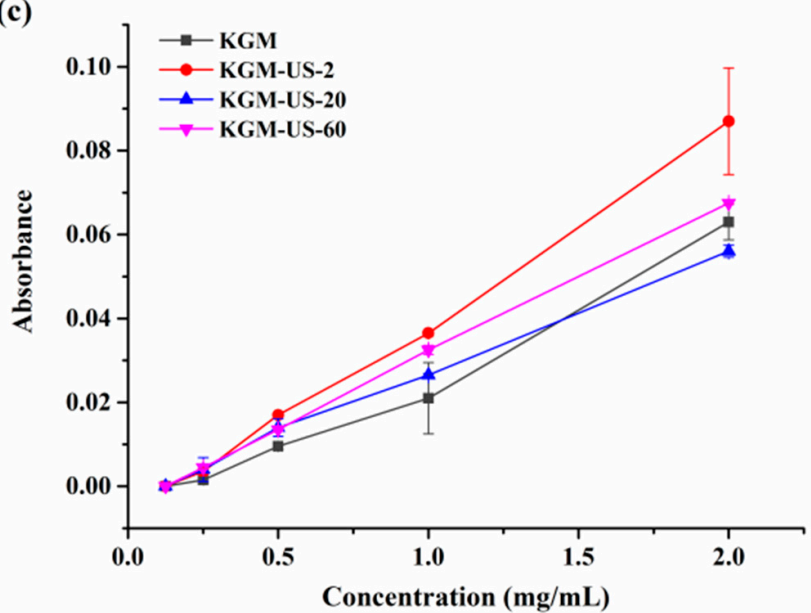

Figure 6. In vitro antioxidant activities of original (KGM) and US-treated KGM (KGM-US-2, KGM-US-20, and KGM-US-60): (a) 2,2'-diphenyl-1-picrylhydrazyl (DPPH) radical-scavenging activity; (b) 2,2'-azino-bis-3-ethyl-benzothiazoline-6-sulphonate (ABTS) radical scavenging activity; (c) ferric-reducing antioxidant power. All values are expressed as means $\pm \mathrm{SD}(n=2)$. Original KGM and US-treated KGM fractions were prepared with distilled water to various concentrations of 0.125 , $0.25,0.5,1.0$, and $2.0 \mathrm{mg} / \mathrm{mL}$.

\section{Conclusions}

The present study showed the alteration of the conformational, microstructural, and antioxidant properties of KGM caused by power US treatment. The original KGM presented a semi-flexible coil conformation and a linear morphology in water. Power US treatment of KGM led to a reduction in the average MW and apparent viscosity, as well as in the size of gel aggregates within a short period of time ( $<10 \mathrm{~min}$ ). Meanwhile, in the time range of 0-10 $\mathrm{min}$, the polydispersity index $M_{\mathrm{W}} / M_{\mathrm{n}}$ value of KGM decreased from 1.5 to 1.2, showing a narrower or more uniform MW distribution. The reduction in MW with time during the US treatment of KGM followed the kinetic model for random chain scission. Compared with the original KGM, the US-degraded KGM had more flexible chain conformation, as well as fragmentary and particulate aggregates with a lower viscosity and Newtonian flow behavior. The US degradation of KGM in most cases resulted in higher radical-scavenging activities. Additionally, the effect of US treatment on the protection of KGM against $\mathrm{H}_{2} \mathrm{O}_{2}$-induced GES-1 cell apoptosis (data not shown) was evaluated, but no significant effect was observed. Overall, this study indicates that power US is a simple and effective means for rapid and partial degradation of high-MW KGM and for modification of the conformation and rheological properties, and enhancement of antioxidant activity.

Supplementary Materials: The following are available online at http:/ /www.mdpi.com/2076-3417/9/3/461/s1: Figure S1: Mark-Houwink plots of KGM following different ultrasonic times. The $L_{\mathrm{p}}$ value was calculated according to the Bohdanecký method by ploting $\left(M^{2} /[\eta]\right)^{1 / 3}$ against $M^{1 / 2}$ (not shown) for each molecular-weight distribution, which was the same as Mark-Houwink plot consideration. Molecular weight distribution selected for the above calculations covered 5-95\% of determined mass for each KGM. KGM treated with ultrasonication is labeled as KGM-US. For example, KGM-US-2 means KGM was subjected to ultrasonication for 2 min at an amplitude of $60 \%$; Figure S2: SEM images of native KGM without US treatment; Table S1: Physicochemical properties and monosaccharide composition of KGM.

Author Contributions: Conceptualization and supervision, J.-Y.W.; data curation, L.-Y.M.; formal analysis, investigation, and writing—original draft, J.-Y.Y.; formal analysis and data curation, L.-Y.M.; methodology, K.-C.S.

Funding: This research received no external funding.

Acknowledgments: This work was financially supported by the National Key R\&D Program of China [2017YFD0400104], the Hong Kong Scholars Program [XJ2016058], Hong Kong Polytechnic University, the Shenzhen Basic Research Project [JCYJ20160531184200806], and the Postdoctoral Science Foundation of Jiangxi Province [2017KY03]. 
Conflicts of Interest: The authors declare no conflicts of interest.

\section{References}

1. An, N.T.; Dong, N.T.; Le Dung, P.; Van Du, N. Characterization of glucomannan from some Amorphophallus species in Vietnam. Carbohyd. Polym. 2010, 80, 308-311. [CrossRef]

2. Katsuraya, K.; Okuyama, K.; Hatanaka, K.; Oshima, R.; Sato, T.; Matsuzaki, K. Constitution of konjac glucomannan: Chemical analysis and ${ }^{13}$ C NMR spectroscopy. Carbohyd. Polym. 2003, 53, 183-189. [CrossRef]

3. Maeda, M.; Shimahara, H.; Sugiyama, N. Detailed examination of the branched structure of konjac glucomannan. Agric. Biol. Chem. 1980, 44, 245-252. [CrossRef]

4. Shimahara, H.; Suzuki, H.; Sugiyama, N.; Nisizawa, K. Isolation and characterization of oligosaccharides from an enzymic hydrolysate of konjac glucomannan. Agric. Biol. Chem. 1975, 39, 293-299. [CrossRef]

5. Zhang, Y.Q.; Xie, B.J.; Gan, X. Advance in the applications of konjac glucomannan and its derivatives. Carbohyd. Polym. 2005, 60, 27-31. [CrossRef]

6. Behera, S.S.; Ray, R.C. Konjac glucomannan, a promising polysaccharide of Amorphophallus konjac K. Koch in health care. Int. J. Biol. Macromo 2016, 92, 942-956. [CrossRef] [PubMed]

7. Herranz, B.; Borderias, A.J.; Solas, M.T.; Tovar, C.A. Influence of measurement temperature on the rheological and microstructural properties of glucomannan gels with different thermal histories. Food. Res. Int. 2012, 48, 885-892. [CrossRef]

8. Ho, H.V.T.; Jovanovski, E.; Zurbau, A.; Mejia, S.B.; Sievenpiper, J.L.; Au-Yeung, F.; Jenkins, A.L.; Duvnjak, L.; Leiter, L.; Vuksan, V. A systematic review and meta-analysis of randomized controlled trials of the effect of konjac glucomannan, a viscous soluble fiber, on LDL cholesterol and the new lipid targets non-HDL cholesterol and apolipoprotein B. Am. J. Clin. Nutr. 2017, 105, 1239-1247. [CrossRef]

9. Xu, X.; Li, B.; Kennedy, J.F.; Xie, B.J.; Huang, M. Characterization of konjac glucomannan-gellan gum blend films and their suitability for release of nisin incorporated therein. Carbohyd. Polym. 2007, 70, 192-197. [CrossRef]

10. Zalewski, B.M.; Chmielewska, A.; Szajewska, H. The effect of glucomannan on body weight in overweight or obese children and adults: A systematic review of randomized controlled trials. Nutrition 2015, 31, 437-442. [CrossRef] [PubMed]

11. Zhu, F. Modifications of konjac glucomannan for diverse applications. Food Chem. 2018, 256, 419-426. [CrossRef] [PubMed]

12. Surina, B.; Tegshi, M.; Taisei, K.; Hideki, N.; Takashi, Y. Sulfation and biological activities of konjac glucomannan. Carbohyd. Polym. 2013, 94, 899-903.

13. Zheng, Q.R.; Wu, Y.L.; Xu, H.L.; Wang, H.J.; Tang, H.L.; Xia, X.J.; Feng, J. Immune responses to Aeromonas hydrophila infection in Schizothorax prenanti fed with oxidized konjac glucomannan and its acidolysis products. Fish. Shellfish. Immun. 2016, 49, 260-267. [CrossRef] [PubMed]

14. Al-Ghazzewi, F.; Elamir, A.; Tester, R.; Elzagoze, A. Effect of depolymerised konjac glucomannan on wound healing. Bioact. Carbohyd. Diet. Fibre 2015, 5, 125-128. [CrossRef]

15. Chen, H.L.; Fan, Y.H.; Chen, M.E.; Chan, Y. Unhydrolyzed and hydrolyzed konjac glucomannans modulated cecal and fecal microflora in Balb/c mice. Nutrition 2005, 21, 1059-1064. [CrossRef]

16. Jian, W.J.; Tu, L.Y.; Wu, L.L.; Xiong, H.J.; Pang, J.; Sun, Y.M. Physicochemical properties and cellular protection against oxidation of degraded Konjac glucomannan prepared by $\gamma$-irradiation. Food Chem. 2017, 231, 42-50. [CrossRef] [PubMed]

17. Mao, Y.H.; Song, A.X.; Yao, Z.P.; Wu, J.Y. Protective effects of natural and partially degraded konjac glucomannan on Bifidobacteria against antibiotic damage. Carbohyd. Polym. 2018, 181, 368-375. [CrossRef]

18. Tatirat, O.; Charoenrein, S.; Kerr, W.L. Physicochemical properties of extrusion-modified konjac glucomannan. Carbohyd. Polym. 2012, 87, 1545-1551. [CrossRef]

19. Mateus, M.M.; Acero, N.F.; Bordado, J.C.; dos Santos, R.G. Sonication as a foremost tool to improve cork liquefaction. Ind. Crop. Prod. 2015, 74, 9-13. [CrossRef]

20. Gogate, P.R.; Prajapat, A.L. Depolymerization using sonochemical reactors: A critical review. Ultrason. Sonochem. 2015, 27, 480-494. [CrossRef]

21. Bera, S.; Mondal, D.; Martin, J.T.; Singh, M. Potential effect of ultrasound on carbohydrates. Carbohyd. Res. 2015, 410, 15-35. [CrossRef] [PubMed] 
22. Ogutu, F.O.; Mu, T.H.; Elahi, R.; Zhang, M.; Sun, H.N. Ultrasonic modification of selected polysaccharides-review. J. Food Process. Technol. 2015, 6, 1-8. [CrossRef]

23. Pu, Y.; Zou, Q.; Hou, D.; Chen, S. Molecular weight kinetics and chain scission models for dextran polymers during ultrasonic degradation. Carbohyd. Polym. 2017, 156, 71-76.

24. Li, J.; Li, B.; Geng, P.; Song, A.X.; Wu, J.Y. Ultrasonic degradation kinetics and rheological profiles of a food polysaccharide (konjac glucomannan) in water. Food Hydrocoll. 2017, 70, 14-19. [CrossRef]

25. Song, A.X.; Mao, Y.H.; Siu, K.C.; Wu, J.Y. Bifidogenic effects of Cordyceps sinensis fungal exopolysaccharide and konjac glucomannan after ultrasound and acid degradation. Int. J. Biol. Macromo 2018, 111, 587-594. [CrossRef] [PubMed]

26. DuBois, M.; Gilles, K.A.; Hamilton, J.K.; Rebers, P.T.; Smith, F. Colorimetric method for determination of sugars and related substances. Anal. Chem. 1956, 28, 350-356. [CrossRef]

27. Bradford, M.M. A rapid and sensitive method for the quantitation of microgram quantities of protein utilizing the principle of protein-dye binding. Anal. Biochem. 1976, 72, 248-254. [CrossRef]

28. Han, F.; Gao, C.; Liu, M.; Huang, F.; Zhang, B. Synthesis, optimization and characterization of acetylated corn starch with the high degree of substitution. Int. J. Biol. Macromo 2013, 59, 372-376. [CrossRef]

29. Willför, S.; Pranovich, A.; Tamminen, T.; Puls, J.; Laine, C.; Suurnäkki, A.; Saake, B.; Uotila, K.; Simolin, H.; Hemming, J. Carbohydrate analysis of plant materials with uronic acid-containing polysaccharides-A comparison between different hydrolysis and subsequent chromatographic analytical techniques. Ind. Crop. Prod. 2009, 29, 571-580. [CrossRef]

30. Liu, X.Y.; Ma, L.Y.; Wang, L.; Wang, X.Y.; Nie, S.P.; Xie, M.Y.; Yin, J.Y. Monosaccharide composition analysis of arabinoxylan by high performance anion exchange chromatography with pulsed amperometric detection. Chin. J. Anal. Chem. 2017, 45, 415-422.

31. Yin, J.Y.; Nie, S.P.; Guo, Q.B.; Wang, Q.; Cui, S.W.; Xie, M.Y. Effect of calcium on solution and conformational characteristics of polysaccharide from seeds of Plantago asiatica L. Carbohyd. Polym. 2015, 124, 331-336.

32. Shimada, K.; Fujikawa, K.; Yahara, K.; Nakamura, T. Antioxidative properties of xanthone on the auto oxidation of soybean in cylcodextrin emulsion. J. Agric. Food Chem. 1992, 40, 945-948. [CrossRef]

33. Chen, C.; Xu, X.M.; Chen, Y.; Yu, M.Y.; Wen, F.Y.; Zhang, H. Identification, quantification and antioxidant activity of acylated flavonol glycosides from sea buckthorn (Hippophae rhamnoides ssp. sinensis). Food Chem. 2013, 141, 1573-1579. [CrossRef] [PubMed]

34. Grönroos, A.; Pirkonen, P.; Ruppert, O. Ultrasonic depolymerization of aqueous carboxymethylcellulose. Ultrason. Sonochem. 2004, 11, 9-12. [CrossRef]

35. Yan, J.K.; Pei, J.J.; Ma, H.L.; Wang, Z.B. Effects of ultrasound on molecular properties, structure, chain conformation and degradation kinetics of carboxylic curdlan. Carbohyd. Polym. 2015, 121, 64-70.

36. Antti, G.; Pentti, P.; Hanna, K. Ultrasonic degradation of aqueous carboxymethylcellulose: Effect of viscosity, molecular mass, and concentration. Ultrason. Sonochem. 2008, 15, 644-648. [CrossRef] [PubMed]

37. Kishida, N.; Okimasu, S.; Kamata, T. Molecular weight and intrinsic viscosity of konjac gluco-mannan. Agric. Biol. Chem. 1978, 42, 1645-1650.

38. Ratcliffe, I.; Williams, P.A.; Viebke, C.; Meadows, J. Physicochemical characterization of konjac glucomannan. Biomacromolecules 2005, 6, 1977-1986. [CrossRef] [PubMed]

39. Kök, M.S.; Abdelhameed, A.S.; Ang, S.; Morris, G.A.; Harding, S.E. A novel global hydrodynamic analysis of the molecular flexibility of the dietary fibre polysaccharide konjac glucomannan. Food Hydrocoll. 2009, 23, 1910-1917. [CrossRef]

40. Wu, T.; Zivanovic, S.; Hayes, D.G.; Weiss, J. Efficient reduction of chitosan molecular weight by high-intensity ultrasound: Underlying mechanism and effect of process parameters. J. Agric. Food Chem. 2008, 56, 5112-5119. [CrossRef]

41. Schmid, G. Zur Kinetik der Ultraschalldepolymerisation. Z. Phys. Chem. 1940, 186, 113-128. [CrossRef]

42. Madras, G.; Kumar, S.; Chattopadhyay, S. Continuous distribution kinetics for ultrasonic degradation of polymers. Polym. Degrad. Stab. 2000, 69, 73-78. [CrossRef]

43. Zhang, L.; Ye, X.; Ding, T.; Sun, X.; Xu, Y.; Liu, D. Ultrasound effects on the degradation kinetics, structure and rheological properties of apple pectin. Ultrason. Sonochem. 2013, 20, 222-231. [CrossRef] [PubMed]

44. Femenia, A.; García-Pascual, P.; Simal, S.; Rosselló, C. Effects of heat treatment and dehydration on bioactive polysaccharide acemannan and cell wall polymers from Aloe barbadensis Miller. Carbohyd. Polym. 2003, 51, 397-405. [CrossRef] 
45. Xing, X.; Cui, S.W.; Nie, S.P.; Phillips, G.O.; Goff, H.D.; Wang, Q. Study on Dendrobium officinale O-acetyl-glucomannan (Dendronan ${ }^{\circledR}$ ): Part I. Extraction, purification, and partial structural characterization. Bioact. Carbohyd. Diet. Fibre 2014, 4, 74-83. [CrossRef]

46. Burchard, W. Two-Dimensional Fourier Transform Infrared Spectroscopy Applied to Cellulose and Paper. In Light Scattering from Polysaccharides, 2nd ed.; Dumitriu, S., Ed.; CRC Press: Boca Raton, FL, USA, 2004; pp. 199-202.

47. Cui, S.W. Food Carbohydrates: Chemistry, Physical Properties, and Applications; CRC Press: Boca Raton, FL, USA, 2005.

48. Picout, D.R.; Ross-Murphy, S.B. On the Mark-Houwink parameters for galactomannans. Carbohyd. Polym. 2007, 70, 145-148. [CrossRef]

49. Kratky, O.; Porod, G. Röntgenuntersuchung gelöster fadenmoleküle. Recueil des Travaux Chimiques des Pays-Bas 1949, 68, 1106-1122. [CrossRef]

50. Bohdanecký, M. New method for estimating the parameters of the wormlike chain model from the intrinsic viscosity of stiff-chain polymers. Macromolecules 1983, 16, 1483-1492. [CrossRef]

51. Tatirat, O.; Charoenrein, S. Physicochemical properties of konjac glucomannan extracted from konjac flour by a simple centrifugation process. LWT-Food Sci. Technol. 2011, 44, 2059-2063. [CrossRef]

52. Xu, W.; Wang, S.; Ye, T.; Jin, W.; Liu, J.; Lei, J.; Li, B.; Wang, C. A simple and feasible approach to purify konjac glucomannan from konjac flour-Temperature effect. Food Chem. 2014, 158, 171-176. [CrossRef]

53. Guo, X.; Ye, X.Q.; Sun, Y.J.; Wu, D.; Wu, N.; Hu, Y.Q.; Chen, S.G. Ultrasound effects on the degradation kinetics, structure, and antioxidant activity of sea cucumber fucoidan. J. Agric. Food Chem. 2014, 62, 1088-1095. [CrossRef] [PubMed]

54. Shi, M.; Yang, Y.; Hu, X.; Zhang, Z. Effect of ultrasonic extraction conditions on antioxidative and immunomodulatory activities of a Ganoderma lucidum polysaccharide originated from fermented soybean curd residue. Food Chem. 2014, 155, 50-56. [CrossRef] [PubMed]

55. Yan, J.K.; Wang, Y.Y.; Ma, H.L.; Wang, Z.B. Ultrasonic effects on the degradation kinetics, preliminary characterization and antioxidant activities of polysaccharides from Phellinus linteus mycelia. Ultrason. Sonochem. 2016, 29, 251-257. [CrossRef] [PubMed]

56. Zhang, H.; Ma, H.; Liu, W.; Pei, J.; Wang, Z.; Zhou, H.; Yan, J. Ultrasound enhanced production and antioxidant activity of polysaccharides from mycelial fermentation of Phellinus igniarius. Carbohyd. Polym. 2014, 113, 380-387. [CrossRef] [PubMed]

57. Zhou, C.; Wang, Y.; Ma, H.; He, R. Effect of ultrasonic degradation on in vitro antioxidant activity of polysaccharides from Porphyra yezoensis (Rhodophyta). Food Sci. Technol. Int. 2008, 14, 479-486. [CrossRef] 